\title{
Research on the Comprehensive Evaluation of Graduate Innovation Ability in Various Regions of China
}

\author{
Qinghua Wang ${ }^{1}$, Lanfang Cheng ${ }^{2}$ and Fengqin Zhang ${ }^{2}$ \\ ${ }^{1}$ Institute of laser engineering, Beijing university of technology, Beijing, 100124 \\ ${ }^{2}$ Institute of economics and management, Beijing university of technology,Beijing, 100124
}

\begin{abstract}
This paper starts from the analysis of the overall situation of postgraduates' innovation ability in our country, and constructs the evaluation index system. By using the method of multivariate clustering analysis, the 31 provinces of our country university innovation ability is divided into four categories, and the regional differences are clearly defined. Furthermore, the weights of each evaluation index are determined by using the entropy weight method, and the comprehensive evaluation results of the innovation ability of graduate students are given.
\end{abstract}

Keywords-graduate innovation ability; the evaluation index; cluster analysis; entropy weight method

\section{INTRODUCTION}

Innovation is to promote national progress and national development of the source and motivation to cultivate innovative talents is the fundamental way to achieve this goal. Graduate education as the highest level of China's higher education, commitment to cultivate high-level specialized personnel and innovative talents of the task. From the development trend, the cultivation of graduate students' innovation ability is not only the core of postgraduate education, but also the dual challenge of globalization of knowledge and science and technology modernization. It is also the inevitable requirement of realizing the strategy of rejuvenating China through science and education and building an innovation country.

\section{The Evaluation Index System of Postgraduates' INNOVATIVE ABILITY}

Taking into account the innovation input and output is the basic elements of innovation, in the design of the evaluation index of international innovation ability is widely used, therefore, in the graduate innovation input indicators, drawing on Yanmin ZHENG [1] and so on, this paper selects the R\&D number in high school the R\&D staff,College R\&D staff hour equivalent, university $R \& D$ funds, respectively measure the creative activities of graduate student human resources, time and money. In the graduate innovation output indicators, drawing on Liang HUANG [2] and Jihong ZHANG [3], Zhongwu HUANG [4], selected topic, the number of R \& D published scientific papers, published works of science and technology, and authorized patent applications to measure the amount of achievements in scientific research; selection of patent ownership transfer and license number, patent ownership transfer and make income to measure the transformation of scientific research achievements. The selection of graduate students innovation ability evaluation index will inevitably be a coincidence content and category, based on the selection of evaluation index to ensure the independence of the index, at the same time to the selected index can from different sides comprehensive measure of regional comprehensive innovation ability[5].

This paper chooses 31 provinces and autonomous regions in China as a research area, in order to summarize the basic situation of Chinese graduate students' innovation ability. Taking into account the availability and reliability of data reflecting innovation capacity, this paper chooses the 2015 data as a sample. All the indicators are derived from the China Statistical Yearbook and the China Education Statistics Yearbook. As part of the data in Hong Kong, Macau and Taiwan is difficult to obtain, it is not considered.

\section{Clustering AnAlysis of GRAdUATE StUdents' INNOVATIVE ABILITY}

The main function of clustering analysis is to classify individuals (samples) or objects (variables) by similarity (distance). The aim is to maximize the homogeneity of individuals in the same class, and to maximize the heterogeneity of classes and individuals. In this paper, we use the clustering analysis method of multivariate statistics to classify the innovation ability of 31 regions in China, and get the pedigree clustering chart in Fig. In order to ensure the rationality of classification, the nonparametric Kruskal-Wallis test was carried out in each cluster category, and the coefficients were significantly larger than 0.05 . The results showed that the classification was reasonable[6]. 


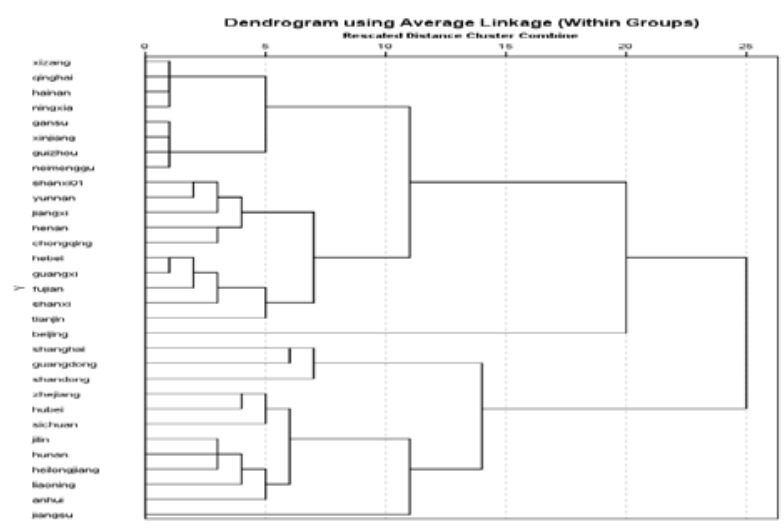

FIGURE I. REGIONAL INNOVATION CAPACITY CLUSTERING RESULTS

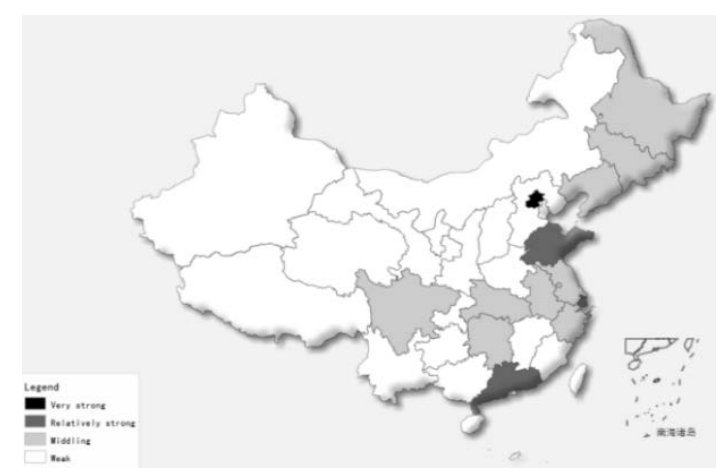

FIGURE II. REGIONAL DISTRIBUTION OF REGIONAL INNOVATION CAPABILITY DIFFERENCE IN CHINA

In determining the optimal number of classification, usually using threshold method, information entropy method, R2 and semi biased R2 method, etc., can also be based on the practical significance of the study to determine the number of categories. At present, there is no uniform standard for using the cluster analysis to determine the optimal number of classifications. In this paper, we select the semi biased R2 method and take into account the development level and development differences of provinces and autonomous regions, and divide the 31 provinces and autonomous regions into four major categories according to regional innovation capability, See Table 1 for details

TABLE I. CHINA'S 31 REGIONAL GRADUATE STUDENTS INNOVATION ABILITY CLUSTERING EVALUATION RESULTS

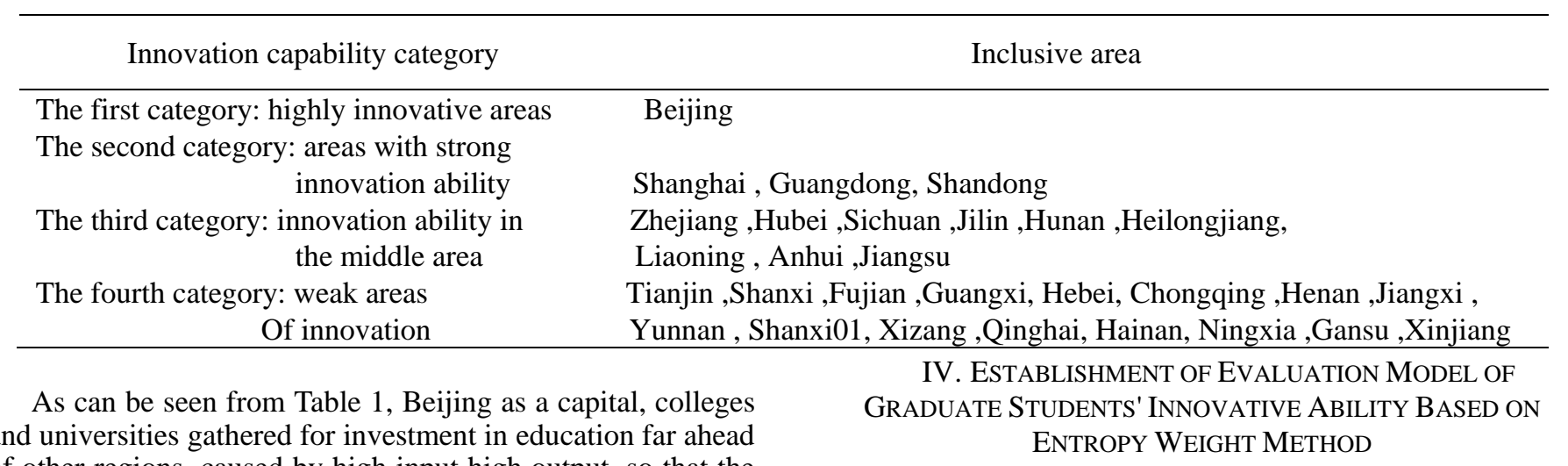
of other regions, caused by high input high output, so that the level of graduate students in the national innovation capacity of the first in the region. From the whole, China's four major regional innovation capacity in the geographical distribution is more concentrated, and presents the basic trend of the East strong West weak, part of the central region, due to the government attaches great importance to education, combined with many colleges and universities, rich educational resources, Leading to its relatively high level of innovation. At the same time, the geographical distribution is given in Figure 2, we can visually see that there is a strong correlation between higher levels of development and economic strength of the region, namely the more developed economies, the higher the level of development of education, universities consequent Graduate students' ability to innovate also increased.
The core idea of entropy weight method is to quantify and synthesize the information of each evaluation unit. The specific steps are broken down as follows:

a) Standardize the original data matrix and determine the target matrix

First of all, suppose there are $\mathrm{m}$ objects to be evaluated $A_{i}(i=1,2,3, \cdots m)$, And there are $n$ evaluation indexes to form the index system, $x_{i j}$ represents the observation value of the $i$ object $A$ under the index $X_{j}$, Thus, the original data matrix is obtained $X=\left(x_{i j}\right)_{m \times n}$ 


$$
X=\left(\begin{array}{cccc}
x_{11} & x_{12} & \cdots & x_{1 n} \\
x_{21} & x_{22} & \cdots & x_{2 n} \\
\vdots & \vdots & \ddots & \vdots \\
x_{m 1} & x_{m 2} & \cdots & x_{m n}
\end{array}\right)
$$

Secondly, calculate the proportion of the index value of the object $A_{i}$ in the $i$ index under the $j$ index $p_{i j}$ :

$$
p_{i j}=x_{i j} / \sum_{i=1}^{m} x_{i j}(j=1,2,3 \cdots n)(1)
$$

Thus the target matrix is obtained $P_{i j}=\left(p_{i j}\right)_{m \times n}$

$$
P=\left(\begin{array}{cccc}
p_{11} & p_{12} & \cdots & p_{1 n} \\
p_{21} & p_{22} & \cdots & p_{2 n} \\
\vdots & \vdots & \ddots & \vdots \\
p_{m 1} & p_{m 2} & \cdots & p_{m n}
\end{array}\right)
$$

Because its elements are between 0 and 1 , it is called standardized matrix.

b) Determine the entropy of each index

The entropy of each evaluation index $X_{j}$ is defined as $e_{j}:$

$$
e_{j}=-k \sum_{i=1}^{m} p_{i j} \ln p_{i j}(j=1,2,3 \cdots n)(2)
$$

among $k=\frac{1}{\ln m}$,for the known constants, It can be proved that the value of $e_{j}$ is between 0 and 1 .

c) Calculate the entropy weight of each index $w_{j}$

According to the entropy value mentioned above, The entropy weight $w_{j}$ of the evaluation index of item $j$ is defined as:

$$
w_{j}=\left(1-e_{j}\right) / \sum_{j=1}^{n}\left(1-e_{j}\right) \quad(j=1,2,3 \cdots n)(3)
$$

so $0 \leq w_{j} \leq 1, \sum_{j=1}^{n} w_{j}=1$, The quality of being weighted.

The entropy weight of a certain index can make the index reflect quantitatively the function of evaluation, and lay the foundation for the following research.

d)Determine the comprehensive weight of each index $\beta_{j}$

The evaluator will determine the index weight of the importance to be $\alpha_{i}$, in which, the entropy weight $w_{j}$ of the index, the comprehensive weight of the index $j$ is:

\begin{tabular}{|c|c|c|c|}
\hline Target layer & The index type & index & eight \\
\hline \multirow{14}{*}{$\begin{array}{c}\text { Innovative } \\
\text { ability } \\
\text { of graduate } \\
\text { students }\end{array}$} & \multirow{7}{*}{$\begin{array}{l}\text { Innovation } \\
\text { investment }\end{array}$} & Number of doctoral candidates & 0.0571 \\
\hline & & Master's degree & 0.0319 \\
\hline & & R\&D personnel total time equivalent & 0.0398 \\
\hline & & Government funds & 0.0732 \\
\hline & & Enterprise funds & 0.0916 \\
\hline & & Foreign capital & 0.2152 \\
\hline & & Subtotal & 0.5088 \\
\hline & \multirow{7}{*}{ Innovation output } & R\&D issues & 0.0437 \\
\hline & & Publish scientific papers & 0.0417 \\
\hline & & Publishing scientific and technical works & 0.0454 \\
\hline & & Invention patent & 0.0663 \\
\hline & & Patent ownership transfer and license number & 0.1100 \\
\hline & & $\begin{array}{l}\text { The transfer of patent ownership and the permitted } \\
\text { income }\end{array}$ & 0.1841 \\
\hline & & Subtotal & 0.4912 \\
\hline
\end{tabular}

$$
\beta_{j}=\frac{\alpha_{j} w_{j}}{\sum_{i=1}^{m} \alpha_{i} w_{i}}(i=1,2,3 \cdots m \quad j=1,2,3 \cdots n)(4)
$$

From this, the weight calculation result of each index is summarized in table 2 .

TABLE II. WEIGHTS OF EACH EVALUATION INDEX

the entropy method, if the weight of an indicator is significant, it shows that the index is more sensitive to the object of evaluation. Table 3 shows that foreign capital, patent ownership transfer and license number, patent ownership transfer and the three indicators of the maximum income are 
the most weighted, respectively $0.2152,0.1100,0.1841$, and explained the importance of them can reflect a strong innovation ability of the area. In the case of other factors constant, foreign capital, patent ownership transfer and license number, patent ownership transfer and make income the greater the value, it will lead to higher scores of comprehensive evaluation of regional, regional comprehensive score is shown in table 4. And can be seen in the subtotal, innovation input innovation output accounted for 0.5088 , accounting for 0.4912, although not flat, but the difference is smaller, indicating a high investment in innovation is brought about by the high regional innovation output, increase innovation investment, to improve the innovation ability of graduate students play an important role.

TABLE III. THE RESULT OF COMPREHENSIVE EVALUATION OF INNOVATION ABILITY IN 31 PROVINCES AND CITIES

\begin{tabular}{|c|c|c|c|c|}
\hline ranking & region & Score & Evaluation result & Include area \\
\hline 1 & Beijing & 148.91 & \multirow{12}{*}{$\begin{array}{l}\text { the ability to innovate is } \\
\text { stronger }\end{array}$} & \multirow{12}{*}{$\begin{array}{l}\text { Beijing, Jiangsu, shanghai, } \\
\text { Guangdong, Tianjin, } \\
\text { Zhejiang, Hubei, Sichuan, } \\
\text { Liaoning, Shanxi, } \\
\text { Heilongjiang, Shandong }\end{array}$} \\
\hline 2 & Jiangsu & 83.26 & & \\
\hline 3 & Shanghai & 75.58 & & \\
\hline 4 & Guangdong & 55.10 & & \\
\hline 5 & Tianjin & 51.09 & & \\
\hline 6 & Zhejiang & 50.52 & & \\
\hline 7 & Hubei & 49.24 & & \\
\hline 8 & Sichuan & 43.78 & & \\
\hline 9 & Liaoning & 41.77 & & \\
\hline 10 & Shanxi & 37.40 & & \\
\hline 11 & Heilongjiang & 37.14 & & \\
\hline 12 & Shandong & 33.37 & & \\
\hline 13 & Anhui & 24.65 & \multirow{19}{*}{$\begin{array}{l}\text { The ability to innovate is } \\
\text { weak }\end{array}$} & \multirow{19}{*}{$\begin{array}{l}\text { Anhui , Hunan, Jilin, } \\
\text { Chongqing, } \\
\text { Henan, Fujian, Hebei, } \\
\text { Guangxi ,Yunnan, Jiangxi, } \\
\text { Shanxi , Gansu , Guizhou, } \\
\text { Xinjiang , Neimenggu, } \\
\text { Ningxia , Hainan ,Qinghai, } \\
\text { Xizang }\end{array}$} \\
\hline 14 & Hunan & 24.48 & & \\
\hline 15 & Jilin & 21.08 & & \\
\hline 16 & Chongqing & 17.50 & & \\
\hline 17 & Henan & 17.03 & & \\
\hline 18 & Fujian & 14.61 & & \\
\hline 19 & Hebei & 12.49 & & \\
\hline 20 & Guangxi & 10.89 & & \\
\hline 21 & Yunnan & 10.07 & & \\
\hline 22 & Jiangxi & 10.06 & & \\
\hline 23 & Shanxi01 & 9.96 & & \\
\hline 24 & Gansu & 6.57 & & \\
\hline 25 & Guizhou & 6.44 & & \\
\hline 26 & Xinjiang & 4.35 & & \\
\hline 27 & Neimenggu & 3.73 & & \\
\hline 28 & Ningxia & 1.80 & & \\
\hline 29 & Hainan & 1.74 & & \\
\hline 30 & Qinghai & 0.97 & & \\
\hline 31 & xizang & 0.95 & & \\
\hline
\end{tabular}

Table 3, according to the scores of each of the 31 regions, the average classification is divided into two categories: innovation ability and weak innovation ability. Thus, innovation ability strong region a total of 12, less than half of the comprehensive innovation ability scores the highest in Beijing, and the special status of the capital Beijing and strong strength of the development of higher education. For Jiangsu,
Shanghai, Guangdong and other regions, the score of innovation ability is far lower than that of Beijing, which has the potential of innovation and development due to its relatively developed economy. Look from the geographical location, the capability of innovation of regional or more concentrated in the eastern coastal areas is the education of many universities in big province, its excellent geographical 
location and abundant education resources become an information and Forum,2017(4);63-72. important factor in innovation ability promotion.

In 19 areas of graduate student innovation ability is weak, more concentrated in the central and western regions of our country, among them, the QingHai and Tibet, two areas of graduate student innovation ability is the worst, the regional innovation ability is weak reason may be that do not have location advantage, and less developed region economy, innovation consciousness is not strong, lead to innovation and development is relatively slow.

\section{CONCLUSIONS AND RECOMMENDATIONS}

In conclusion, the comprehensive evaluation of graduate student innovation capability in different regions in China, the research results show that our country university graduate student innovation ability regions present state of development is not balanced, obvious regional differences. The main conclusions are summarized as follows:

The regional innovation capability is similar, and the innovation capacity of the region varies widely. Clustering analysis to our country's 31 provinces and autonomous regions are divided into four categories, the Beijing outshine others, graduate student innovation ability with absolute advantage in the first, Beijing should make full use of the resources advantage, do a good job in the national model; Secondly, the eastern coastal areas and some education provinces in the central region are not as innovative. Although they are not as high as Beijing's, the future potential is endless. For the western region, the graduate student innovation ability level is significantly below the national average, need the support of national policy and the education resources, and, not blindly follow other areas in western China, belong to the region education policy, the introduction of talent, the development of education, improving regional innovation ability, to narrow the difference with the national, in order to promote the increase of the innovation ability.

\section{ACKNOWLEDGEMENTS}

This paper is supported by Beijing Research Base of Social Science Fund Project (15JDJGC016) and BJUT RiXin Fund Project (011000514117013).

\section{REFERENCE}

[1] Zheng Yanmin, Zhang Wei, Han Yong. Research on the relationship between regional innovation input, output and innovation environment empirical analysis based on provincial interface data [J]. Scientific and technological progress and countermeasures, 2012 (15); 35-41.

[2] Huang Liang, Wang Zhen, Fan Fei. Measurement and analysis of scientific and technological innovation capability of 50 cities in the Yangtze River Economic Zone Based on catastrophe progression model [J]. Statistical information and Forum,2017(4);73-79.

[3] Zhang Jihong, Luo Yuzhong. The index system of national integrated innovation capability evaluation [J].Reform,2009(10),80-84.

[4] Huang Zhongwu. Spatial distribution and spatial spillover of technological innovation in China and its impact on regional economic growth [D]. Xiamen: Overseas Chinese university,2014.

[5] ZhangAi li, Li Yueming. Analysis of regional innovation ability difference based on classification [J]. Scientific and technological progress and countermeasures,2016(10);28-33.

[6] Xia Weili, Ding Peiqi Study on the evaluation index system of innovation and entrepreneurship environment in China [J]. Statistical 